\title{
LETTERS
}

\section{Maternal infection can cause spontaneous abortion}

In their CMAJ article, Muanda and colleagues ${ }^{1}$ found that exposure to antibiotics during pregnancy was associated with an increased risk of spontaneous abortion. A key question is whether this association is causal or not. We believe the study findings are suggestive of confounding by indication.

Maternal infections can cause spontaneous abortion in early pregnancy. ${ }^{2} \mathrm{Com}$ paring women who received antibiotics to those who did not is therefore problematic. This is not extinguished by the authors' secondary analysis in which the comparator was women exposed to penicillin or cephalexin, because those exposed to other antibiotics, such as fluoroquinolones, may simply have had different infections.

The possibility of confounding by indication is further suggested by the supplementary analysis in which no association was seen between antibiotics given for respiratory tract infections. If antibiotics were independently associated with spontaneous abortion, an association should have been apparent in this analysis.

\section{Jonathan S. Zipursky MD}

Fellow, Clinical Pharmacology and

Toxicology, University of Toronto,

Toronto, Ont.

\section{Alex Cressman MD MSc}

Resident Physician, Faculty of Medicine, University of Toronto, Toronto, Ont.

\section{David N. Juurlink MD PhD}

Professor, Departments of Medicine and Pediatrics, University of Toronto;

Scientist, Institute for Clinical Evaluative Sciences, Toronto, Ont.

- Cite as: CMAJ 2017 August 8;189:E1021. doi: $10.1503 /$ cmaj. 733203

\section{References}

1. Muanda FT, Sheehy O, Berard A. Use of antibiotics during pregnancy and risk of spontaneous abortion. CMAJ 2017;189:E625-33.

2. Goldenberg RL, McClure EM, Saleem S, et al. Infection-related stillbirths. Lancet 2010;375:1482-90.

Competing interests: None declared. 